\title{
Utility of fractional exhaled nitric oxide suppression as a prediction tool for progression to biologic therapy
}

\author{
Claire A. Butler ${ }^{1}$, Alan J. McMichael ${ }^{2}$, Kirsty Honeyford ${ }^{1}$, Louise Wright ${ }^{1}$, Jayne Logan ${ }^{1}$, Joshua Holmes ${ }^{2}$, \\ John Busby ${ }^{2}$, Catherine E. Hanratty ${ }^{1}$, Freda Yang $^{3}$, Steven J. Smith ${ }^{3}$, Kirsty Murray ${ }^{3}$, Rekha Chaudhuri ${ }^{3}$ and \\ Liam G. Heaney ${ }^{1,2}$ on behalf of the Medical Research Council UK Refractory Asthma Stratification \\ Programme (RASP-UK)
}

${ }^{1}$ Belfast City Hospital, Belfast, UK. ${ }^{2}$ Queen's University Belfast, Belfast, UK. ${ }^{3}$ Gartnavel General Hospital and University of Glasgow, Glasgow, UK.

Corresponding author: Liam G. Heaney (l.heaney@qub.ac.uk)

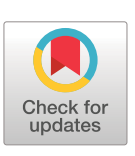

Copyright (CThe authors 2021

This version is distributed under the terms of the Creative Commons Attribution NonCommercial Licence 4.0. For commercial reproduction rights and permissions contact permissions@ersnet.org

This article has supplementary material available from openres.ersjournals.com

Received: 23 April 2021

Accepted: 11 June 2021

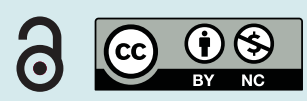

Shareable abstract (@ERSpublications)

A positive $F_{\text {ENO }}$ suppression test can identify non-adherence. Maintenance of "optimised" $F_{\text {ENO }}$ by sustained adherence to inhaled therapy predicts patients who are likely to maintain control with high-dose inhaled therapy without the need for biologics. https://bit.ly/3cRpQ5B

Cite this article as: Butler CA, McMichael AJ, Honeyford K, et al. Utility of fractional exhaled nitric oxide suppression as a prediction tool for progression to biologic therapy. ERJ Open Res 2021; 7 : 00273-2021 [DOI: 10.1183/23120541.00273-2021].

\section{Abstract}

Rationale: The utility of fractional exhaled nitric oxide $\left(F_{\text {ENO }}\right)$ suppression (FeNOSuppT) to identify nonadherence to inhaled corticosteroid (ICS) treatment has previously been reported, but whether it can predict clinical outcome remains unclear.

Objectives: We examined the utility of FeNOSuppT in prediction of progression to biologic agents or discharge from specialist care.

Methods: FeNOSuppT was measured at home using remote monitoring technology of inhaler use alongside daily $F_{\text {ENO }}$ measurement over 7 days. Long-term clinical outcomes in terms of progression to biologic agent or discharge from specialist care were compared for non-suppressors and suppressors.

Measurements and main results: Of the 162 subjects, 135 successfully completed the test with 81 (60\%) positive $F_{\text {ENO }}$ suppression tests. Subjects with a negative FeNOSuppT were more likely to proceed to biologic therapy (39 of 54 patients, 72\%) compared to those with a positive FeNOSuppT (35 of 81 patients, 43\%, $\mathrm{p}=0.001$ ). In subjects with a positive FeNOSuppT, predictors of progression to biologic therapy included higher dose of maintenance steroid at initial assessment and prior intensive care unit admission. These subjects had a significant rise in $F_{\text {ENO }}$ between post-suppression test and follow-up (median, 33 (IQR 25-55) versus 71 (IQR 24-114); p=0.009), which was not explained by altered corticosteroid dose.

Conclusions: A negative FeNOSuppT correlates with progression to biologic therapy. A positive

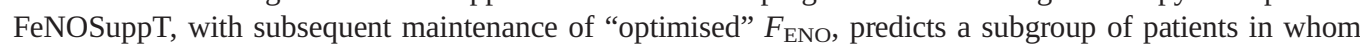
asthma control is preserved with adherence to high-dose ICS/long-acting $\beta 2$ agonist and who can be discharged from specialist care.

\section{Introduction}

Severe asthma consumes a disproportionate amount of the healthcare costs attributable to asthma, and much of this is due to the medication costs, management of exacerbations and unscheduled healthcare usage $[1,2]$. Suboptimal adherence remains a significant barrier to asthma control across the spectrum of asthma severity and contributes to an increased risk of exacerbation [3]. Identification of non-adherence can be difficult as patient self-report is often overestimated, and collection of prescriptions does not always equate with use $[4,5]$.

Both fractional exhaled nitric oxide $\left(F_{\mathrm{ENO}}\right)$ and peripheral blood eosinophil count $(\mathrm{PBE})$ are markers of Type 2 (T2) asthma, and elevated $F_{\text {ENO }}$ is reported to predict the likelihood of response to inhaled 
corticosteroids (ICS) and risk of future exacerbations [6, 7]. The $F_{\text {ENO }}$ suppression test (FeNOSuppT) can identify poor background adherence to ICS in patients with "difficult-to-control” asthma [8], and we have previously demonstrated its utility as a "home-based" test using smart inhaler technology in predicting biomarker profile and suitability for biologic therapy when patients are adherent to high-dose ICS/ long-acting $\beta 2$ agonist (LABA) treatment [9]. The availability of biologic agents targeting specific cytokines in the inflammatory cascade has led to improved control and reduced corticosteroid exposure in patients with T2-high asthma [10], and small single centre cohort studies have suggested that a positive FeNOSuppT is associated with lower transition to biologic therapy [11, 12]. Biologics are costly and potentially life-long, therefore it is important to manage other conditions impacting upon asthma control and ensure patients are adherent to inhaled corticosteroids (ICS) prior to committing to biologic agents. The purpose of this study was to examine longer term outcomes following FeNOSuppT in a multicentre setting and determine whether subjects with a positive test experienced an improvement in exacerbation frequency and were less likely to proceed to biologic treatment; in essence, could a 7-day assessment of adherence help predict future outcome in terms of progression to biologic therapy?

\section{Methods}

This was a retrospective analysis of 162 subjects attending the Difficult Asthma Centres in Belfast and Glasgow who underwent $F_{\text {ENO }}$ suppression testing as part of the UK Refractory Asthma Stratification Program (RASP-UK) between September 2014 and October 2018 [9]. The Health Research Authority Research UK Ethics Committee and the Research Leads of participating centres approved the study as a clinical service evaluation in the RASP-UK programme, and FeNOSuppT is now embedded in routine clinical assessment.

All subjects had "difficult-to-control” asthma inadequately controlled on Global Initiative for Asthma (GINA) Step 4 or already prescribed Step 5 treatment [13] and were referred for specialist assessment and potential biologic therapy. All patients had detailed systematic assessment by a difficult asthma specialist multi-disciplinary team. As part of this assessment, patients with a $F_{\text {ENO }} \geqslant 45 \mathrm{ppb}$ proceeded to FeNOSuppT as originally described $[8,9]$.

FeNOSUppT using remote monitoring was performed using the INCA $^{\circledR}$ device (INhaler Compliance Assessment, Vitalograph, Ennis, Ireland) attached to the Diskus ${ }^{\circledR}$ (GlaxoSmithKline UK Ltd) inhaler [14] (see online supplementary material for further detail). In brief, this device has been previously described and utilises time- and date-stamped acoustic monitoring technology (sound file) of inhaler technique, alongside daily $F_{\text {ENO }}$ measurement using the Niox VERO ${ }^{\circledR}$ machine (Circassia UK, Oxford, UK) [14]. Use of the Diskus ${ }^{\circledR}$ and $F_{\text {ENO }}$ machine was demonstrated to subjects by appropriately trained staff within the clinic setting. Subjects were asked to measure their $F_{\text {ENO }}$ each day, followed by inhalation of high-dose inhaled corticosteroid (fluticasone $1000 \mu \mathrm{g}$ daily) via the Flixotide “500” Diskus ${ }^{\circledR}$ (GlaxoSmithKline) with an INCA $^{\circledR}$ device attached for 7 days alongside their "usual” ICS/LABA inhaler as previously described [8]. Subjects returned to the clinic on Day 7 and data from the INCA ${ }^{\circledR}$ device were uploaded and analysed via the Vitalograph IC Data Compression Utility server (with additional input of $F_{\text {ENO }}$ readings, eosinophils and Asthma Control Questionnaire (ACQ) result) and an overall adherence measure obtained. The output included information on doses received, technique errors, percentage adherence and baseline versus Day 7

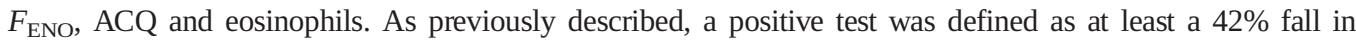
$F_{\text {ENO }}$ between Day 0/ Day 1 and the Day 4/ Day 5 mean $F_{\text {ENO values [8] }}$

The key clinical outcomes were progression to biologic therapy and discharge from specialty care. In the UK, biologic access is determined by the National Institute for Health and Care Excellence (NICE) and is defined by use of maintenance oral corticosteroids or frequent exacerbations ( $\geqslant 3$ per year) in severe eosinophilic asthma [15-17]. For all subjects, demographic, clinical and biomarker data were obtained at initial clinical attendance and following FeNOSuppT; in subjects who progressed to biologics, clinical and biomarker data at initiation of the biologic were obtained, and in subjects who did not progress to biologics, data from their last clinical review were obtained as available.

\section{Statistical analysis}

Normally distributed variables are presented as mean and standard deviation, and independent $t$-tests were used to compare between groups. Non-normally distributed variables are presented as median and interquartile, and Mann-Whitney U-tests were used to compare between groups. Chi-squared analysis was used to perform hypothesis tests among categorical variables. Within-person changes in T2-biomarkers and corticosteroids between the FeNOSuppT and end of follow-up were compared using paired t-tests and McNemar test. Mixed-effect linear and logistic regression models were used to contrast the differences in the within-person changes between patients progressing to biologic therapy and those who did not. In these 
models the primary parameter of interest was the interaction term between time period (post-suppression test versus follow-up) and biologic progression status. In all models $F_{\text {ENO }}$ and blood eosinophils were analysed on the log scale due to their positive skew; hence, effect estimates were presented as ratios. Multivariable logistic regression modelling was used to determine predictors of progressing to biologic therapy.

\section{Results}

\section{Patient characteristics}

Patient disposition and baseline demographic characteristics are shown in figure 1 and table 1. Of the original 162 subjects, 27 (17\%) were unable to perform a suppression test (10 - no daily $F_{\text {ENO }} 17$ inadequate ICS dose during 7-day FeNOSuppT). Of the 135 subjects who successfully performed a $F_{\text {ENO }}$ suppression test, 81 (60\%) were positive and 54 (40\%) were negative. There were more females (67\% versus $44 \%, \mathrm{p}=0.010$ ), younger subjects (mean age: 41 years versus 49 years, $\mathrm{p}=0.002$ ), with a higher prevalence of eczema ( $23 \%$ versus $7 \%, \mathrm{p}=0.017)$ and greater symptom burden (ACQ-5: 3.1 versus 2.4, $\mathrm{p}=0.004$ ) in the positive group (table 1). There was no significant difference in the proportion on maintenance prednisolone ( $56 \%$ versus $62 \%, \mathrm{p}=0.441$ ), rescue prednisolone courses in the prior 12 months (3 or more courses: $54 \%$ versus $57 \%, \mathrm{p}=0.917$ ) or T2-biomarkers (blood eosinophils (cells $10^{9}$ per $\mathrm{L}$ ) median: 0.42 versus $0.38, \mathrm{p}=0.967 ; F_{\mathrm{ENO}}(\mathrm{ppb})$ median: 87 versus $83, \mathrm{p}=0.420$ ) between subjects with a positive and negative FeNOSuppT (table 1).

\section{Outcome following FeNOSuppT}

A positive FeNOSuppT was associated with greater likelihood of discharge from specialist care (25 of 81 (31\%) positive FeNOSuppT versus 4 of 54 (7\%) negative FeNOSuppT, p=0.001) (figure 1). Discharge would indicate improved asthma control not requiring intervention with biologics or other specialist input. For those that were discharged, this happened much more quickly among those with a positive FeNOSuppT than negative FeNOSuppT (median: 343 versus 808 days, $\mathrm{p}<0.010$ ). In contrast, a negative FeNOSuppT was significantly associated with progressing to biologics (35 of 81 (43\%) positive FeNOSuppT versus 39 of $54(72 \%)$ negative FeNOSuppT, p=0.001) (figure 1). There was no significant

Suppression testing and long-term outcome - is it clinically useful?

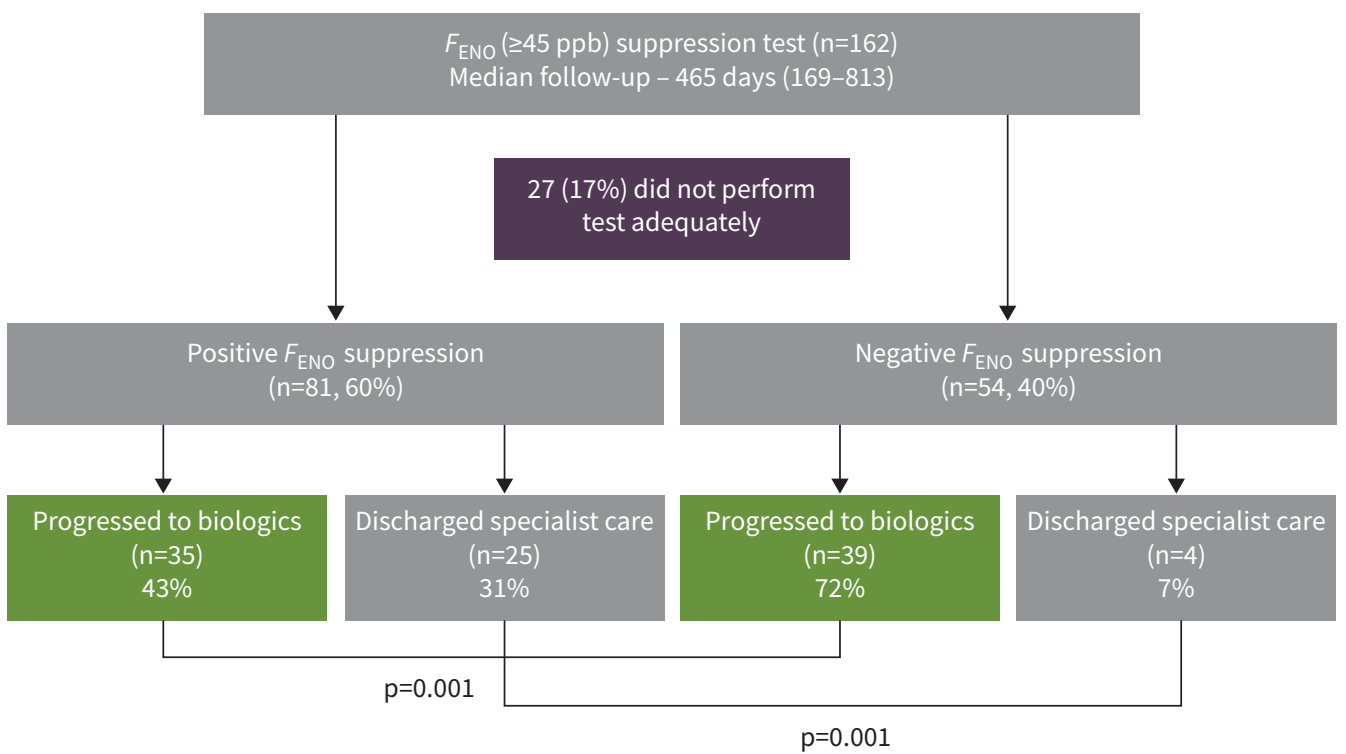

FIGURE 1 Flow chart showing the disposition of participants assessed by severe asthma services in Belfast and Glasgow ( $n=162$ ) with a fractional exhaled nitric oxide $\left(F_{\mathrm{ENO}}\right)$ of $>45 \mathrm{ppb}$ despite treatment at Step 4 or 5 of the BTS/SIGN guidelines. Participants were asked to measure their $F_{\text {ENO }}$ each day for 7 days followed by inhalation of high-dose inhaled corticosteroid (fluticasone $1000 \mu \mathrm{g}$ daily) via the Diskus with an INCA device. A positive suppression test was categorised as at least a 45\% decrease in $F_{\mathrm{ENO}}$ between Day 0/Day 1 and the Day 4/Day 5 mean $F_{\mathrm{ENO}}$ values. In those with a positive $F_{\mathrm{ENO}}$ suppression test, 21 subjects $(26 \%)$ remained in specialist care but not on biologics, compared to 11 subjects $(20 \%)$ in those with a negative suppression test remaining in specialist care but not on biologics. 
TABLE 1 Demographic characteristics at baseline assessment of the 135 subjects with fractional exhaled nitric oxide $\left(F_{\text {ENO }}\right)>45 \mathrm{ppb}$ who successfully performed a $F_{\text {ENO }}$ suppression test (FeNOsuppT)

\begin{tabular}{|c|c|c|c|}
\hline & \multicolumn{3}{|c|}{ Baseline data } \\
\hline & Positive $F_{\mathrm{ENO}}$ suppression & Negative $F_{\mathrm{ENO}}$ suppression & p-value \\
\hline Subjects & 81 & 54 & \\
\hline Female & $54(67)$ & $24(44)$ & 0.010 \\
\hline Age years & $41 \pm 15.4$ & $49 \pm 13.1$ & 0.002 \\
\hline \multicolumn{4}{|l|}{ Smoking status } \\
\hline Never-smoker & $58(72)$ & $38(72)$ & 0.503 \\
\hline Ex-smoker & $21(26)$ & $15(28)$ & \\
\hline Current smoker & $2(2)$ & $0(0)$ & \\
\hline Atopic ${ }^{\#}$ & $50(63)$ & $31(58)$ & 0.643 \\
\hline ACQ-5 & $3.1 \pm 1.3$ & $2.4 \pm 1.3$ & 0.004 \\
\hline$F_{\text {ENO }} \mathrm{ppb}$ & $87(65-128)$ & $83(60-111)$ & 0.420 \\
\hline Blood eosinophils, cells $10^{9}$ per L & $0.42(0.20-0.62)$ & $0.38(0.25-0.63)$ & 0.967 \\
\hline Inhaled steroid (BDP equivalent $\mu \mathrm{g}$ ) & $2000(1600-2000)$ & $2000(1600-2000)$ & 0.626 \\
\hline Maintenance prednisolone & $45(56)$ & $33(62)$ & 0.441 \\
\hline Prednisolone dose $\mathrm{mg}$ & $10(7.5-15)$ & $10(8.75-13.75)$ & 0.678 \\
\hline \multicolumn{4}{|l|}{ Prednisolone boost (past 12 months) } \\
\hline 0 & $19(24)$ & $11(21)$ & 0.917 \\
\hline $1-2$ & $18(23)$ & $12(23)$ & \\
\hline 3 or more & $43(54)$ & $30(57)$ & \\
\hline Hospital admission past 12 months & $28(35)$ & $12(23)$ & 0.140 \\
\hline Ever in ICU & 7 (9) & $6(11)$ & 0.608 \\
\hline Eczema & $19(23)$ & $4(7)$ & 0.017 \\
\hline Chronic rhinosinusitis with nasal polyps ${ }^{q}$ & $25(31)$ & $18(34)$ & 0.743 \\
\hline $\mathrm{FEV}_{1} \%$ pred & $76.0 \pm 19.8$ & $72.5 \pm 17.6$ & 0.301 \\
\hline FVC \% pred & $93.2 \pm 17.2$ & $87.9 \pm 16.9$ & 0.084 \\
\hline $\mathrm{FEV}_{1} / \mathrm{FVC} \%$ & $67.0 \pm 11.7$ & $65.9 \pm 11.1$ & 0.580 \\
\hline IgE IU $\cdot L^{-1}$ & $197(60-731)$ & $147(85-274)$ & 0.252 \\
\hline
\end{tabular}

difference between the median time taken to progress to biologics between subjects who had a positive or negative suppression test (median, 588 days versus 455 days; $\mathrm{p}=0.658$ ).

\section{Biomarker and steroid treatment - post-suppression test to follow-up}

To further characterise subjects in both groups who progressed to biologic therapy, we compared biomarker and steroid treatment post-suppression test to their pre-biologic data (or follow-up data for those who did not progress to biologics) (table 2).

\section{Positive FeNOSUPPT}

In those subjects with a positive FeNOSuppT who progressed to biologics, predictors of progression were maintenance prednisolone at baseline (table 3, 27 of $35(80 \%)$ versus 18 of $46(39 \%), \mathrm{p}<0.001)$ and a higher dose (12.5 (10-20) mg versus 8.75 (5-10) mg, p=0.014) than those who did not progress; however, there was little difference in prednisolone rescue courses in the prior 12 months (table 3). Interestingly, these subjects with a positive FeNOSuppT who progressed to biologic treatment had a significant rise in $F_{\text {ENO }}$ between post-suppression test and follow-up (median 33 (25-55) versus 71 (24114); $\mathrm{p}=0.009$ ), which was not explained by altered steroid dose (table 2, difference-in-differences analysis), but little change in PBE (figure 2). However, in subjects with a positive FeNOSuppT who did not progress to biologic therapy, $F_{\mathrm{ENO}}$ and blood eosinophil count remained relatively unchanged with inhaled steroid optimisation despite a substantial reduction in the proportion on oral steroids (from $n=14$ to 4 in whom data available) (figure 2). In the four subjects with a positive FeNOSuppT remaining on maintenance prednisolone who did not proceed to biologics, two had significant hypothalamic-pituitaryadrenal (HPA) axis suppression and remained on $5 \mathrm{mg}$ prednisolone replacement dose with stable asthma 
TABLE 2 Comparison of fractional exhaled nitric oxide $\left(F_{\text {ENO }}\right)$, blood eosinophils, inhaled corticosteroids (ICS) dose and proportion on maintenance oral corticosteroids (OCS) for positive and negative $F_{\text {ENO }}$ suppressors

Progressed to biologics

n Post-suppression Follow-up

test
Did not progress to biologics

p-value $n$ Post-suppression

test
Follow-up

p-value

Difference-in-differences analysis est. $(95 \% \mathrm{Cl}$;

p-value); maintenance OCS presented as odds ratio (OR)
Difference-in-differences analysis adjusted for maintenance

prednisolone at baseline est. ( $95 \% \mathrm{Cl}$; p-value)

\begin{tabular}{|c|c|c|c|c|c|c|c|c|c|c|}
\hline \multicolumn{11}{|l|}{ Positive } \\
\hline$F_{\text {ENO }} \mathrm{ppb}$ & 34 & $33(25-55)$ & $71(24-114)$ & 0.009 & 33 & $25(19-37)$ & $32(23-42)$ & 0.215 & $29.9(11.1-48.7 ; p=0.002)$ & $28.3(8.8-47.6 ; p=0.004)$ \\
\hline $\begin{array}{l}\text { Blood eosinophils, } \\
\text { cells } 10^{9} \text { per L }\end{array}$ & 27 & $0.32(0.19-0.49)$ & $0.24(0.05-0.50)$ & 0.122 & 19 & $0.45(0.14-0.71)$ & $0.38(0.11-0.62)$ & 0.359 & $-0.08(-0.3-0.14 ; p=0.480)$ & $\begin{array}{c}-0.05(-0.28-0.18 \\
p=0.664)\end{array}$ \\
\hline $\begin{array}{l}\text { ICS dose (BDP } \\
\text { equivalent } \mu \mathrm{g})\end{array}$ & 35 & $2000(1600-2000)$ & $2000(2000-2000)$ & 0.146 & 36 & $1600(800-2000)$ & 2000 (2000-2000) & 0.007 & $75.2(-295.5-446 ; p=0.691)$ & \\
\hline Maintenance OCS & 34 & $27(80)$ & $28(82)$ & 0.655 & 35 & $14(40)$ & $4(11)$ & 0.002 & $\begin{array}{c}\mathrm{OR}=62.4(2.4-1613.2 \\
\mathrm{p}=0.015)\end{array}$ & \\
\hline \multicolumn{11}{|l|}{ Negative } \\
\hline$F_{\text {ENO }} \mathrm{ppb}$ & 38 & $53(37-75)$ & $68(43-104)$ & 0.143 & 13 & $39(33-52)$ & $50(27-65)$ & 0.388 & $\begin{array}{c}12.96(-21.62-47.55 ; \\
p=0.463)\end{array}$ & $\begin{array}{c}11.37 \begin{array}{l}(-24.05-46.80 \\
\mathrm{p}=0.529)\end{array}\end{array}$ \\
\hline $\begin{array}{l}\text { Blood eosinophils, } \\
\text { cells } 10^{9} \text { per L }\end{array}$ & 28 & $0.34(0.16-0.74)$ & $0.19(0.09-0.56)$ & 1.000 & 8 & $0.24(0.12-0.41)$ & $0.37(0.24-0.50)$ & 0.289 & $-0.22(-0.61-0.15 ; p=0.251)$ & $\begin{array}{c}-0.21(-0.25-0.14 \\
p=0.249)\end{array}$ \\
\hline $\begin{array}{l}\text { ICS dose (BDP } \\
\quad \text { equivalent } \mu \mathrm{g})\end{array}$ & 37 & $2000(1600-2000)$ & $2000(2000-2000)$ & $<0.001$ & 14 & $1800(1200-2000)$ & $2000(2000-2000)$ & 0.289 & $\begin{array}{c}142.3(-216.7-501.4 \\
p=0.437)\end{array}$ & \\
\hline Maintenance OCS & 38 & $25(66)$ & $28(74)$ & 0.180 & 14 & $8(57)$ & $6(43)$ & 0.414 & $\mathrm{OR}=5.8(0.39-86.5, \mathrm{p}=0.195)$ & \\
\hline
\end{tabular}

Maintenance $\mu \mathrm{g}$ )

$28(74)$

$0.180 \quad 14$

$8(57)$

$6(43)$

$0.414 \quad \mathrm{OR}=5.8(0.39-86.5, \mathrm{p}=0.195)$

Values shown are median (IQR) or $\mathrm{n}(\%)$, unless otherwise stated. $F_{\mathrm{ENO}}$, blood eosinophil and ICS dose values are compared using paired sample sign tests. McNemar's test was used for within group comparison of people on maintenance prednisolone; odds ratios are presented. Difference-in-differences analysis compares the change among those who progressed to biologics to those who did not progress and is derived from mixed effects linear regression ( $F_{\mathrm{ENO}}$, blood eosinophils and ICS dose) or logistic regression (maintenance prednisolone use) models. 
TABLE 3 Demographic characteristics for subjects who had a positive suppression result (FeNOsuppT), categorised by whether they progressed to biologics or not

Patients with positive FeNOSuppT

Progressed to biologics Did not progress to biologics

\begin{tabular}{|c|c|c|c|}
\hline Subjects $n$ & 35 & 46 & \\
\hline Female & $22(63)$ & $32(70)$ & 0.526 \\
\hline Age years & $42.4 \pm 13.7$ & $40.0 \pm 16.7$ & 0.491 \\
\hline \multicolumn{4}{|l|}{ Smoking status } \\
\hline Never-smoker & $25(71)$ & $33(72)$ & 0.981 \\
\hline Ex-smoker & $9(26)$ & $12(26)$ & \\
\hline Current smoker & $1(3)$ & $1(2)$ & \\
\hline Atopic ${ }^{\#}$ & $21(62)$ & $29(63)$ & 0.901 \\
\hline Ever in ICU & $7(20)$ & $0(0)$ & 0.002 \\
\hline Eczema & $8(23)$ & $11(24)$ & 0.912 \\
\hline Chronic rhinosinusitis with nasal polyps & $13(38)$ & $12(26)$ & 0.247 \\
\hline $\operatorname{lgE} I U \cdot L^{-1}$ & $177(43-801)$ & $197(64-592)$ & 0.960 \\
\hline \multicolumn{4}{|l|}{ Baseline assessment at initial clinic visit } \\
\hline ACQ-5 (baseline) & $3.07 \pm 1.26$ & $3.09 \pm 1.35$ & 0.959 \\
\hline$F_{\text {ENO }} \mathrm{ppb}$ (baseline) & $91(65-111)$ & $83(63-130)$ & 0.958 \\
\hline Blood eosinophils cells $10^{9}$ per $\mathrm{L}$ & $0.33(0.18-0.62)$ & $0.43(0.21-0.62)$ & 0.412 \\
\hline Inhaled steroid (BDP equivalent $\mu \mathrm{g}$ ) & $2000(1600-2000)$ & $2000(1200-2000)$ & 0.170 \\
\hline Maintenance prednisolone & $27(80)$ & $18(39)$ & $<0.001$ \\
\hline Prednisolone dose mg & $12.5(10-20)$ & $8.75(5-10)$ & 0.014 \\
\hline \multicolumn{4}{|l|}{ Prednisolone boost past 12 months } \\
\hline 0 & $9(26)$ & $10(22)$ & 0.706 \\
\hline $1-2$ & $9(26)$ & $9(20)$ & \\
\hline 3 or more & $17(49)$ & $26(58)$ & \\
\hline Hospital admission past 12 months & $14(40)$ & $14(30)$ & 0.370 \\
\hline $\mathrm{FEV}_{1} \%$ pred & $71.1 \pm 19.4$ & $79.6 \pm 19.5$ & 0.056 \\
\hline FVC \% pred & $88.2 \pm 17.0$ & $96.9 \pm 16.6$ & 0.024 \\
\hline $\mathrm{FEV}_{1} / \mathrm{FVC} \%$ & $64.4 \pm 12.4$ & $68.9 \pm 10.8$ & 0.090 \\
\hline \multicolumn{4}{|l|}{ Follow-up (pre-biologic assessment) } \\
\hline Time to follow-up days & $538 \pm 403$ & $445 \pm 562$ & 0.475 \\
\hline $\begin{array}{l}\text { Maintenance prednisolone } \\
\text { Data not available } n=12\end{array}$ & $28(82)$ & $4(11)$ & $<0.001$ \\
\hline Prednisolone dose mg & $10(10-15)$ & $10(5-15)$ & 0.040 \\
\hline \multicolumn{4}{|l|}{ Prednisolone boost (past 12 months) } \\
\hline \multicolumn{4}{|l|}{ Data not available $n=18$} \\
\hline 0 & $3(10)$ & $19(58)$ & $<0.001$ \\
\hline $1-2$ & $8(27)$ & $12(36)$ & \\
\hline 3 or more & $19(63)$ & $2(6)$ & \\
\hline Inhaled steroid (BDP equivalent $\mu \mathrm{g}$ ) & $2000(2000-2000)$ & $2000(2000-2000)$ & 0.023 \\
\hline Hospital admission (past 12 months) & $7(20)$ & $4(11)$ & 0.276 \\
\hline
\end{tabular}

Data are shown as median (interquartile range), mean \pm SD or $\mathrm{n}(\%)$ as appropriate, unless otherwise indicated. ICU: intensive care unit; IgE: immunoglobulin E; ACQ: Asthma Control Questionnaire; $F_{\mathrm{ENO}}$ : fractional exhaled nitric oxide; $\mathrm{FEV}_{1}$ : forced expiratory volume in $1 \mathrm{~s}$; FVC: forced vital capacity. \#: atopy defined with immunology test; skin prick or RAST positive to inhaled allergen (cat, dog, house dust mite, mixed grasses); `: chronic rhinosinusitis with nasal polyps diagnosed after specialist otolaryngology assessment.

and no prednisolone boosts, one developed giant cell arteritis requiring maintenance prednisolone and sarilumab, and one patient did not wish to consider biologic therapy.

\section{Negative FeNOSUppT}

In those with a negative suppression test, there was little change in biomarker profile post-suppression or asthma control at follow-up despite inhaled steroid optimisation and little reduction in the proportion on oral steroids (table 2). In the 15 subjects who did not progress to biologics, eight remained biomarker high but fell short of UK prescribing criteria for biologic therapy (which dictates $>3-4$ courses of rescue prednisolone per year, or the need for maintenance prednisolone), one did not wish to progress immediately to biologic therapy and six remained on maintenance prednisolone. Of these six, one patient was diagnosed with human leukocyte antigen (HLA) B27-negative axial inflammatory 

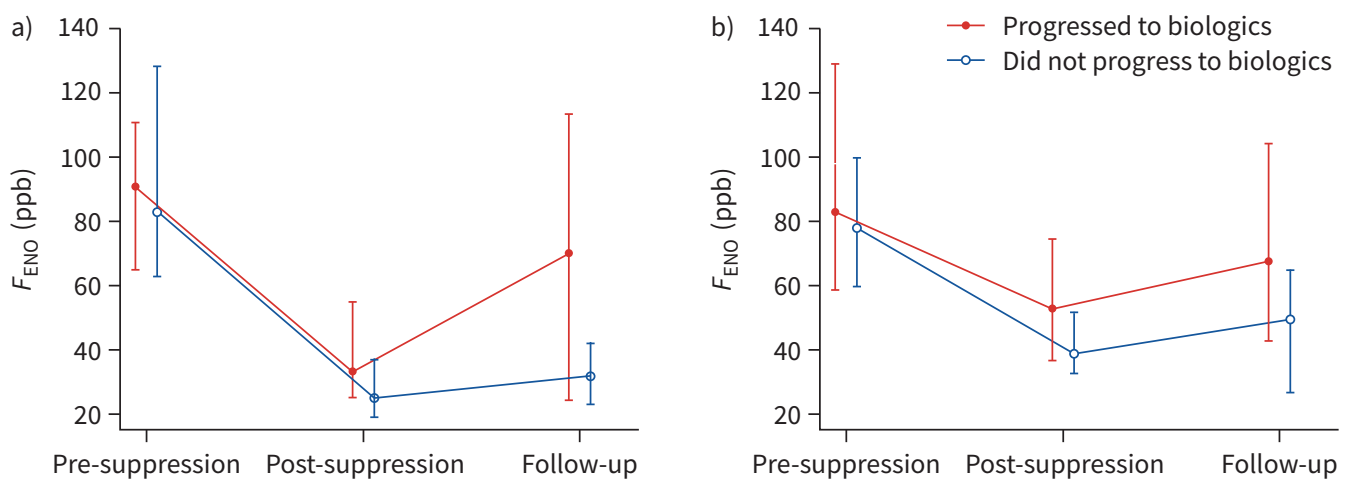

FIGURE 2 Fractional exhaled nitric oxide $\left(F_{\mathrm{ENO}}\right)$ suppression curves (shown as median values, interquartile range) for subjects with initial $F_{\text {ENO }}>45 \mathrm{ppb}$ and a) a positive suppression test $(\mathrm{n}=81)$ and b) a negative suppression test $(n=54)$. There was a significant increase in post-suppression and follow-up $F_{\text {ENO }}$ values for patients with a positive suppression test who progressed to biologics $(p=0.009)$.

spondyloarthropathy and started on secukinumab (anti-interleukin (IL)-17) and prednisolone, three had HPA axis suppression therefore could not withdraw prednisolone (and asthma remained stable) and two did not wish to initiate biologic therapy.

\section{Predictors of progression to biologics}

To explore predictors of progression to biologic therapy, multivariable analysis was performed using the following variables (age, sex, suppression test (positive or negative), exacerbation rate $(0,1-2, \geqslant 3$ ), maintenance prednisolone (y/n), intensive care unit (ICU) (y/n), ACQ $(<0.75,0.75-1.5,>1.5), F_{\text {ENO }}<84$, $\geqslant 84 \mathrm{ppb}$ (median value), forced expiratory volume in $1 \mathrm{~s} /$ forced vital capacity \%). At initial assessment, only a negative suppression test (OR 6.9, 95\% CI 2.1-22.1; $\mathrm{p}<0.001$ ) and being on maintenance prednisolone (OR 3.7, 95\% CI 1.4-10.1; $\mathrm{p}=0.010$ ) predicted progression to biologic therapy. There was no difference in predictive variables and progression to biologic therapy between clinical centres.

\section{Discussion}

Non-adherence, whether intentional or non-intentional, is common in all severities of asthma, and assessment and management of poor adherence is integral to good asthma care in asthma clinical guidelines [13, 18]. At present there is no standardised approach to identifying non-adherence, and identification varies from patient-reported adherence, which is known to substantially overestimate adherence [4], prescription records [5] to more sophisticated means such as the use of monitored inhaler devices aligned with biomarker profiling $[9,14]$. The original description of FeNOSuppT identified that in patients on maximal high-dose ICS with multiple other controllers and with a baseline $F_{\text {ENO }}$ of $>45 \mathrm{ppb}$, following directly observed treatment with additional inhaled corticosteroid identified non-adherence (see supplementary material for details) [8]. In the current study, $60 \%$ of subjects referred to the severe asthma centres for consideration of biologics had a positive FeNOSuppT, suggesting that suboptimal adherence remains a major issue and is consistent with prior descriptions of the problem in this clinical population [5, 9 , 19]. The identification of non-adherence is particularly important prior to commitment to complex long-term treatments such as biologic therapies. In a US prescribing database study looking at 7658 prevalent and 3399 incident omalizumab users, 48.6\% had very low adherence (medication possession ratio for ICS and/or ICS-LABA $\leqslant 50 \%$ ) in the 12 months prior to omalizumab initiation [20], suggesting that biologic therapy is used to manage non-adherence to inhaled treatment where it is not identified before biologic initiation.

This study looked at long-term clinical outcome defined as progression to biologic therapy or discharge from specialist care and demonstrated that FeNOSuppT identified patients more likely to proceed to biologic therapy or to be discharged from specialist care controlled with optimised inhaled treatment (figure 1). At baseline patients presented similarly - biomarker high with a high prevalence of concomitant maintenance prednisolone and frequent exacerbations; however, these patients can be "dichotomised" with FeNOSuppT into those for whom early consideration to biologics should be given if appropriate, and those who require a further period of assessment as to the appropriate clinical course (figure 1). 
Corticosteroid stewardship is a major focus for healthcare providers, and this study suggests that poor adherence to inhaled therapies is often managed with inappropriate oral corticosteroid prescription. Of particular note, 10 of 14 patients with a positive FeNOSuppT, who were prescribed maintenance prednisolone at the point of initial specialist asthma assessment and did not progress to biologics, managed to withdraw prednisolone simply with optimised inhaled treatment, and in the remaining four, three required prednisolone for another condition and one did not wish to proceed to biologic therapy. Therefore in all but one patient in this group who did not progress to biologic therapy, their underlying asthma did not dictate an ongoing need for maintenance prednisolone; additionally the one remaining patient would have proceeded to biologic therapy with their consent. These data builds on the report of FARUQI et al. [11] who described 6-month outcome in 46 patients who fulfilled UK prescribing criteria for biologic therapy; following FeNOSuppT, 19 of 46 (40\%) were identified as non-adherent and 14 did not progress to biologic therapy during the 6-month follow-up. Notably, in this cohort, none were on maintenance oral corticosteroid at initial assessment, whereas in our cohort over $50 \%$ were prescribed maintenance prednisolone, which is typical of patients referred to specialist care in the UK [21]. BoDDY et al. [12] described an analysis of patients who underwent either FeNOSuppT $(n=42)$ or remote monitoring over a 28-day period, and again fewer patients who "suppressed" their $F_{\text {ENO }}$ proceeded to biologic therapy compared with non-suppressors (35.5\% versus $72.7 \%$ ).

It is important to note that FeNOSuppT is a phenotyping exercise to identify non-adherence, and specifically patients who are likely to be responsive to high-dose ICS. It is not a suggested intervention to maintain adherence, and notably in those with a positive FeNOSuppT who eventually progressed to biologic therapy, there was a significant rise in $F_{\mathrm{ENO}}$ at the pre-biologic start date compared to the value on completion of the 7-day FeNOSuppT, which was not explained by change in corticosteroid prescription (oral prednisolone or ICS) (figure 2). We have previously shown that this Day 7 value is closely related to the "optimised" value when adherent with high-dose ICS/LABA [9], and notably this increase in $F_{\text {ENO }}$ was not seen in those with a positive FeNOSuppT who did not progress to biologic therapy, despite significant reduction in maintenance prednisolone exposure. Taken together, this suggests that there is a reversion to previous suboptimal adherence to high-dose ICS in those with positive FeNOSuppT who progress to biologic therapy, and whether this could be prevented with an adherence support system, e.g. a connected inhaler system with real-time feedback, is an area for future research [22]. There is evidence that suboptimal adherence to inhaled maintenance treatment is common at time of initiation of biologic therapy [20] and additionally is associated with biologic failure [23]. Data from these studies were based upon prescription collection, but this is a less accurate way to assess adherence when compared to objective FeNOSuppT [8].

In parallel, these data demonstrate that negative FeNOSuppT was predictive of progression to biologics, suggesting this test is useful in quickly discriminating refractory T2-high patients likely to require these more advanced therapies (figure 1). Patients with a negative suppression test who did not progress to biologics remained biomarker high despite high-dose ICS treatment and/or maintenance oral prednisolone, and there were other reasons for not proceeding to biologic therapy, such as falling short of UK prescribing access criteria or the inability to wean steroids due to HPA axis suppression.

We have previously described the demographic features of patients with a positive FeNOSuppT [8], and this cohort again demonstrated the association of a positive FeNOSuppT with younger female patients and a greater prevalence of eczema; importantly maintenance corticosteroid use, yearly prednisolone boosts and biomarker profile were not different to those with a negative FeNOSuppT. However, these data also identified within the group with a positive FeNOSuppT potential predictors at initial presentation of likely progression to biologic treatment including being on maintenance prednisolone at higher dose (median $12.5 \mathrm{mg}$ versus $8.75 \mathrm{mg}$ ), with a higher proportion having had a previous ICU admission. At the time of progression to biologic therapy, patients with a positive FeNOSuppT were more likely to continue maintenance prednisolone and remained exacerbation-prone as evidenced by prednisolone boosts, which is consistent with the UK access criteria to biologic therapy. It is important to note, as discussed above, potential slippage in adherence to ICS is likely to contribute to failure to withdraw prednisolone.

Patients with a positive FeNOSuppT were more likely to be discharged from clinic and in a shorter time frame. Consistently “optimised” $F_{\text {ENO }}$ levels post-suppression testing in this subgroup are consistent with ongoing good adherence to high-dose ICS treatment and are consistent with withdrawal of maintenance prednisolone and exacerbation reduction ( $58 \%$ had no exacerbations requiring prednisolone boost in the 12 months prior to their follow-up data collection). This suggests that not only is FeNOSuppT useful in predicting biologic need, but it can also support the clinician in an adherence intervention and corticosteroid stewardship in a proportion of patients. The time to commence a biologic in this study was 
long and in part reflects the timing of clinical assessment (including FeNOSuppT) and NICE approval of access to suitable biologic agents with many patients, whether positive or negative FeNOSuppT, on a wait list pending NICE approval in the UK.

The strength of these data includes a "real world" multicentre approach and a standardised assessment of adherence at the outset, and outcomes were entirely consistent between the two centres. Although patients were able to demonstrate effective use of the Diskus ${ }^{\circledR}$ inhaler at the initiation of FeNOSuppT, 17 (10\%) had ineffective dosing during the test in keeping with previous observations [8]; however, FeNOSuppT is deliverable in routine clinic care for the majority of patients. There are also a number of limitations to the data. The result of the FeNOSuppT was not "blinded" to the clinical team and may have impacted clinical decision making to progress to biologic therapy. However, the fact that a proportion of patients with a positive FeNOSuppT did progress to biologic therapy suggests that this was not a specific barrier. Asthma control measured by ACQ was available for all patients at time of FeNOSuppT, and in all those progressing to biologic therapy; however, there were inconsistent data for long-term follow-up in those who did not progress to biologics or were discharged as symptom control was determined by clinical assessment rather than formal ACQ.

In summary, this study suggests that FeNOSuppT is a valuable step in the assessment of the exacerbation-prone difficult-to-control asthmatic patient presenting with a high $F_{\text {ENO }}\left(F_{\text {ENO }} \geqslant 45 \mathrm{ppb}\right)$. It facilitates short-term profiling of biomarker responses to ICS to identify those who are likely to respond better to high-dose ICS/LABA therapy when used regularly ("positive" suppressors) and those who, despite good adherence to inhaled treatment, are likely to require additional treatment with biologic agents ("negative suppressors"). Future studies should explore if adherence support tools, such as connected inhaler devices, will further reduce progression to biologic therapy and should include health economic analyses of this approach to help streamline the approach to assessment of this population.

Acknowledgements: The authors are grateful to the medical teams that provided support with the tests: Belfast Health and Social Care Trust (John Lindsay and Jacqui Gamble) and Gartnavel General Hospital, Greater Glasgow Health Board (Heather Beck).

Conflict of interest: C.A. Butler reports Vitalograph provided support for the INCA device used to assess adherence during the conduct of the study; and fees for lectures from AstraZeneca and GlaxoSmithKline, and conference support from NAPP and Chiesi, outside the submitted work. A.J. McMichael has nothing to disclose. K. Honeyford has nothing to disclose. L. Wright has nothing to disclose. J. Logan has nothing to disclose. J. Holmes has nothing to disclose. J. Busby has nothing to disclose. C.E. Hanratty has nothing to disclose. F. Yang has nothing to disclose. S.J. Smith has nothing to disclose. K. Murray has nothing to disclose. R. Chaudhuri reports advisory board meeting fees, a research grant, speaker fees and conference travel support from AstraZeneca; advisory board meeting and speaker fees from GSK, Teva, Novartis and Chiesi; and conference travel support from Napp Pharmaceuticals, all outside the submitted work. L.G. Heaney reports sponsorship for attending international scientific meetings from AstraZeneca, Boehringer Ingelheim, Chiesi, GSK and Napp Pharmaceuticals; personal fees for lectures and advisory boards from Novartis, Hoffman la Roche/Genentech Inc., Sanofi, Evelo Biosciences, GlaxoSmithKline, AstraZeneca, Teva, Theravance and Circassia; and institutional grant funding from Medimmune, Novartis UK, Roche/Genentech Inc. and GlaxoSmithKline; and is Academic Lead for the Medical Research Council Stratified Medicine UK Consortium in Severe Asthma, which involves Industrial Partnerships with Amgen, Genentech/Hoffman la Roche, AstraZeneca, Medimmune, GlaxoSmithKline, Aerocrine and Vitalograph, all outside the submitted work.

Support statement: This study was supported by Medical Research Council grant RASP-UK. Funding information for this article has been deposited with the Crossref Funder Registry.

\section{References}

$1 \quad$ Zeiger RS, Schatz M, Dalal AA, et al. Utilization and costs of severe uncontrolled asthma in a managed-care setting. J Allergy Clin Immunol Pract 2016; 4: 120-129.e3.

2 Barry LE, Sweeney J, O'Neill C, et al. The cost of systemic corticosteroid-induced morbidity in severe asthma: a health economic analysis. Respir Res 2017; 18: 129.

3 Heaney LG, Horne R. Non-adherence in difficult asthma: time to take it seriously. Thorax 2012; 67: 268-270.

4 Patel M, Perrin K, Pritchard A, et al. Accuracy of patient self-report as a measure of inhaled asthma medication use. Respirology 2013; 18: 546-552.

5 Gamble J, Stevenson M, McClean E, et al. The prevalence of nonadherence in difficult asthma. Am J Respir Crit Care Med 2009; 180: 817-822. 
6 Van Rensen ELJ, Straathof KCM, Veselic-Charvat MA, et al. Effect of inhaled steroids on airway hyperresponsiveness, sputum eosinophils, and exhaled nitric oxide levels in patients with asthma. Thorax 1999; 54: 403-408.

7 Kimura $\mathrm{H}$, Konno $\mathrm{S}$, Makita $\mathrm{H}$, et al. Prospective predictors of exacerbation status in severe asthma over a 3-year follow-up. Clin Exp Allergy 2018; 48: 1137-1146.

8 McNicholl DM, Stevenson M, McGarvey LP, et al. The utility of fractional exhaled nitric oxide suppression in the identification of nonadherence in difficult asthma. Am J Respir Crit Care Med 2012; 186: 1102-1108.

9 Heaney LG, Busby J, Bradding P, et al. Remotely monitored therapy and nitric oxide suppression identifies nonadherence in severe asthma. Am J Respir Crit Care Med 2019; 199: 454-464.

10 McGregor MC, Krings JG, Nair P, et al. Role of biologics in asthma. Am J Respir Crit Care Med 2019; 199: 433-445.

11 Faruqi S, Zhou S, Thompson J, et al. Suppression of F ENO with observed inhaled corticosteroid therapy in severe asthma: is it a useful test in clinical practice? ERJ Open Res 2019; 5: 00123-02019.

12 Boddy CE, Naveed S, Craner M, et al. Clinical outcomes in people with difficult-to-control asthma using electronic monitoring to support medication adherence. J Allergy Clin Immunol Pract 2021; 9: 1529-1538.e2.

13 Global Initiative for Asthma (GINA). Global strategy for Asthma Management and Prevention. 2020. Available from: https://ginasthma.org/.

14 Sulaiman I, Greene G, Machale E, et al. A randomised clinical trial of feedback on inhaler adherence and technique in patients with severe uncontrolled asthma. Eur Respir J 2018; 51: 1701126.

15 National Institute for Health and Care Excellence (NICE). Omalizumab for treating severe persistent allergic asthma. www.nice.org.uk/guidance/ta278 Date last updated: March 2016. Date last accessed: 13 December 2020.

16 National Institute for Health and Care Excellence (NICE). Mepolizumab for treating severe refractory eosinophilic asthma. www.nice.org.uk/guidance/ta431 Date last updated: January 2020. Date last accessed: 13 December 2020.

17 National Institute for Health and Care Excellence (NICE). Reslizumab for treating severe eosinophilic asthma. www.nice.org.uk/guidance/TA479 Date last updated: July 2021. Date last accessed: 13 December 2020.

18 BTS/SIGN. British guideline on the management of asthma 2019 | British Thoracic Society | Better lung health for all. www.brit-thoracic.org.uk/about-us/pressmedia/2019/btssign-british-guideline-on-the-management-ofasthma-2019 Date last updated: July 2019. Date last accessed: 13 December 2020.

19 Murphy AC, Proeschal A, Brightling CE, et al. The relationship between clinical outcomes and medication adherence in difficult-to-control asthma. Thorax 2012; 67: 751-753.

20 Jeffery MM, Shah ND, Karaca-Mandic $P$, et al. Trends in omalizumab utilization for asthma: evidence of suboptimal patient selection. J Allergy Clin Immunol Pract 2018; 6: 1568-1577.e4.

21 Sweeney J, Patterson CC, Menzies-Gow A, et al. Comorbidity in severe asthma requiring systemic corticosteroid therapy: cross-sectional data from the optimum patient care research database and the British Thoracic Difficult Asthma Registry. Thorax 2016; 71: 339-346.

22 Moore A, Preece A, Sharma R, et al. A connected inhaler system improves adherence to fluticasone furoate/ vilanterol in asthma. Eur Respir J 2019; 54: OA3561.

23 D'Ancona G, Kavanagh J, Roxas C, et al. Adherence to inhaled corticosteroids and clinical outcomes in mepolizumab therapy for severe asthma. Eur Respir J 2020; 55: 1902259. 